\title{
"Sabe com quem está falando?" heterogeneidades e posicionamentos discursivos inscritos no discurso aristocrático da elite brasileira
}

\author{
Robson Figueiredo Brito* \\ Fernanda Zilli do Nascimento ${ }^{\star \star}$
}

\begin{abstract}
Resumo
Este trabalho propôs uma descrição dos posicionamentos discursivos inscritos na pauta do "sabe com quem está falando?” da formação discursiva da aristocracia da elite brasileira. Para tanto, analisaram-se três cenas enunciativas, gravadas em vídeos e amplamente divulgados pela mídia, nas quais indivíduos foram interpelados por uma ordem de um agente do Estado, mas se recusaram a acatá-la. A partir dos pressupostos da Análise de Discurso, tomamos as noções de sujeito do discurso, formação discursiva e de pré-construído para descrever quais foram os modos de dizer pelos quais os indivíduos indiciaram sua identificação com o discurso da elite brasileira. A análise demonstrou que o indivíduo se identifica com a formação discursiva do "sabe com quem está falando?" assumindo estratégias bélicas que se assentam em: desqualificar o seu oponente; filiar-se a outras vozes hierarquicamente superiores; projetar um ethos que faz supor um poder maior do que o de seu adversário com o objetivo de estabilizar o seu lugar de poder e vencer o seu interlocutor.

Palavras-chave: Formação discursiva. Sabe com quem está falando?. Posicionamento discursivo.
\end{abstract}

\footnotetext{
* Pontifícia Universidade Católica de Minas Gerais. Doutor em Linguística e Língua Portuguesa. ORCID https://orcid.org/0000-0003-0557-3185.

** Pontifícia Universidade Católica de Minas Gerais. Doutoranda em Linguística e Língua Portuguesa. ORCID: https://orcid.org/0000-0002-0392-3113.
}

Cadernos CESPUC de Pesquisa. Série Ensaios. n.37, $2^{\circ}$ Sem./2020, p. 26-44. e-ISSN: 2358-3231 (OJS). Recebido em: 07/10/2020. Aceito em: 19/10/2020. 


\title{
"Do you know who you are Talking to?" Heterogeneities and Discursive Positions Included in the Aristocratic Discourse of the Brazilian High Class
}

\author{
Robson Figueiredo Brito
}

Fernanda Zilli do Nascimento

\begin{abstract}
This paper proposed a description of the discursive positions inscribed on the agenda "do you know who you're talking to?" of the discursive formation of the aristocracy of the Brazilian elite. To this end, three enunciative scenes, recorded on videos and widely disseminated by the media were analyzed which showed individuals questioned by an order from a State agent, but refused to comply with it. From the assumptions of Discourse Analysis, we take the notions of subject of discourse, discursive formation and pre-built to describe what were the ways of saying by which individuals indicated their identification with the discourse of the Brazilian elite. The analysis showed that the individual identifies with the discursive formation of "do you know who you're talking to?" assuming warlike strategies that are based on: disqualifying your opponent; join other hierarchically superior voices; to project an ethos that assumes a power greater than that of its opponent in order to stabilize its place of power and overcome its interlocutor.
\end{abstract}

Keywords: Discursive formation. Do you know who you are talking to?. Discursive positioning. 


\section{Introdução}

Este ensaio tratou de examinar as cenas enunciativas e os posicionamentos discursivos flagrados em três vídeos que circularam amplamente em redes e mídias sociais no primeiro semestre de 2020, no Brasil. Os vídeos apresentaram situações distintas com diferentes sujeitos empíricos; mas há neles um fio condutor que os atravessa e, desse modo, costura sua unicidade: os discursos que eles põem em circulação, da ordem do "sabe com quem está falando?", se inscrevem em uma formação discursiva da aristocracia de poder da elite brasileira ${ }^{1}$. As cenas enunciativas que compõem nosso corpus tornaram-se, desse modo, um acontecimento discursivo analisável, uma vez que os efeitos de sentido ali produzidos foram acionados por meio da memória histórica do pré-construído, do já dito (ORLANDI, 1999).

Os princípios basilares de nossa discussão se assentam nos Estudos Dialógicos da Linguagem, considerando os conceitos de dialogia, de subjetividade e de heterogeneidade (VOLÓCHINOV, 2017; BAKHTIN, 2011), pois, subjacente a essa proposta, reside o pressuposto de que

[...] na relação criadora com a língua, não existem palavras sem voz, palavras de ninguém. Em cada palavra há vozes infinitamente distantes, anônimas, quase impessoais (as vozes dos matizes lexicais, dos estilos, etc.) quase imperceptiveis, e vozes próximas, que soam concomitantemente. (BAKTHIN, 2011, p. 330).

No esteio das considerações sobre a heterogeneidade da linguagem, Authier-Revuz (2004) nos lembra que todas as palavras já foram ditas em algum lugar da história e, por isso, estão impregnadas de valores ideológicos, modificando o seu sentido em função do momento, do uso e do lugar discursivo do enunciador; assim "sempre sob as palavras, 'outras palavras' são ditas: é a estrutura material da língua que permite que, na linearidade de uma cadeia (discursiva), se faça escutar a polifonia não intencional de todo discurso" (AUTHIER-REVUZ, 2004, p. 28).

\footnotetext{
1 A noção de aristocracia foi tomada em consonância com os trabalhos de DaMatta (1997), que defende que a elite brasileira se estrutura na pauta da pessoalidade, do respeito, da honra, do favor e da consideração pessoal. Como exemplo, o uso do “sabe com quem está falando?", no Brasil, configura-se como uma prática discursiva cujo efeito de sentido visado é o de projetar o poder econômico e o social legitimados no indivíduo, em sua intelectualidade e na configuração de sua rede de relações de amizade e de influências.
}

"Sabe com quem está falando?" heterogeneidades e 28 posicionamentos discursivos inscritos no discurso aristocrático da elite brasileira 
Para empreendermos nossa análise, tomamos também as noções de sujeito do discurso, de formação discursiva e de pré-construído ${ }^{2}$ da Análise do Discurso (AD) de orientação francesa (PÊCHEUX, 1995; MAINGUENEAU, 1997; ORLANDI, 2007, 1999) para a qual o sujeito é - e está - sempre interpelado e atravessado por outras vozes e outros jáditos $^{3}$. Em uma cena enunciativa, ao convocar e mobilizar enunciados marcadamente pertencentes a determinadas formações discursivas, o sujeito indicia a sua adesão, ou mesmo a sua vontade de pertencimento, àqueles regimes de verdade e de poder.

Assumimos como orientação metodológica o paradigma indiciário ${ }^{4}$, que nos oferece os dispositivos de leitura desses vídeos que permitem desvelar vestígos, índices e marcas linguístico-discursivas presentes nos posicionamentos discursivos construídos pelos sujeitos falantes flagrados nas cenas enunciativas selecionadas.

\section{Apontamentos de ordem teórica}

Este ensaio traz, em seu cerne, a discussão sobre as noções de sujeito, heterogeneidade discursiva e posicionamentos discursivos. Assumimos, conforme Pêcheux (1995), que o indivíduo é interpelado enquanto sujeito pela ideologia, e essa compreensão de sujeito é central na relação entre discurso, língua e produção de sentidos. O discurso segue o ritual da palavra com seus movimentos de sentido, com os erros dos sujeitos, com as zonas provisórias de conjunção e dispersão, de unidade, de incerteza, de ancoragem.

Ainda em Pêcheux (1995, p. 163, grifo do autor):

\footnotetext{
2 O conceito de pré-construído se mostra produtivo para esta análise, pois observamos no enunciado as marcas - por meio dos adjetivos, modalizadores, orações relativas - do discurso anterior, o "já-dito", acionado na memória discursiva do sujeito.

3 Assinalamos que trouxemos vozes-outras para indicar que já estamos respondendo ao já-dito proposto na chamada desta revista: dialogicidade e heterogeneidade das e nas práticas de linguagem.

4 Consideramos que a gênese do paradigma indiciário estabelecido por Ginzburg (1986, p. 157) está expresso na condição da (im)possibilidade de o historiador obter o conhecimento direto da realidade quando afirma que: "se a realidade é opaca, existem zonas privilegiadas - sinais, indícios - que permitem decifrá-la". O autor se refere à natureza o conhecimento histórico, no qual lemos, como conhecimento das ciências humanas, ao afirmar que: "E, como o do médico, o conhecimento histórico é indireto, indiciário e conjectural. [...] Mas o conjunto das ciências humanas permaneceu solidamente ancorado no qualitativo." (GINZBURG, 1986, p. 165). Concordamos com Tfouni e Pereira (2018, p. 128) que: "A relação entre o dizer e o sentido é indireta, devido à opacidade da linguagem" e que o analista do discurso deve sempre levar em conta os modos de dizer do sujeito do discurso.
} 
A interpelação do indivíduo em sujeito de seu discurso se efetua pela identificação (do sujeito) com a formação discursiva que o domina (isto é, na qual ele é constituído como sujeito): essa identificação, fundadora da unidade (imaginária) do sujeito, apoia-se no fato de que os elementos do interdiscurso (sob sua dupla forma, descrita mais acima, enquanto "pré-construído" e "processo de sustentação") que constituem, no discurso do sujeito, os traços daquilo que o determina, são re-inscritos no discurso do próprio sujeito.

Nessa direção, interrogar-se sobre como os discursos funcionam é colocar-se na encruzilhada de um duplo jogo da memória: o da memória institucional, que estabiliza e cristaliza, e, ao mesmo tempo, o da memória constituída pelo esquecimento, que torna possível o diferente, a ruptura, o outro (ORLANDI, 1999). Assim, ao trabalho do analista do discurso interessa o homem falando e a palavra em movimento, ou, como afirma Orlandi (1999, p. 16, grifo nosso), o analista do discurso "considera os processos e as condições de produção da linguagem, pela análise da relação estabelecida pela língua com os sujeitos que a falam e as situações em que se produz o dizer". Analisar a discursividade de um texto implica considerá-lo como uma materialidade simbólica própria e significativa que coloca em funcionamento a relação do sujeito com os sentidos que constituem os “[...] processos de identificação do sujeito, de argumentação, de subjetivação, de construção da realidade" (ORLANDI, 1999, p. 21).

Em nossos estudos (BRITO, 2019), ressaltamos que Bakhtin argumenta que o emprego da língua acontece sob forma de enunciados, tanto orais quanto escritos, concretos e únicos, que são integrados aos mais diversos campos da atividade humana: “[...] cada enunciado particular é individual, mas cada campo de utilização da língua elabora seus tipos relativamente estáveis de enunciados, os quais denominamos gêneros do discurso" (BAKHTIN, 2011, p. 12). Cabe integrar os argumentos de Authier Revuz (2004, p. 98) sobre os "processos reais da constituição de um discurso", que incidem sobre a noção de heterogeneidade enunciativa, ancorada na concepção de que o discurso é atravessado pela linguagem.

Nessa linha de pensamento, a heterodiscursividade da linguagem é permeada pela diversidade que marca o discurso e, por isso, percebemos que essa concepção, tal qual afirma a autora, "se articula àquela do sujeito que não é uma entidade homogênea exterior à linguagem” (AUTHIER 
REVUZ, 2004, p. 26) e também se apoia na heterogeneidade constitutiva que se organiza em torno das "formas linguísticas de representação de diferentes modos de negociação do sujeito falante com a heterogeneidade constitutiva do seu discurso, o que se denomina heterogeneidade marcada" (p. 32).

Por último, tomamos o constructo psicanalítico de identificação projetiva como uma ferramenta essencial para a análise dos dados. Essa lente de análise nos possibilitou compreender os meios pelos quais os indivíduos, durante as cenas analisadas, acionam um tipo de mecanismo de defesa projetivo que faz instaurar a agressividade nos modos de dizer e nos movimentos gestuais.

No processo de enunciação, o sujeito do discurso é atravessado pelo sujeito do inconsciente em um processo de ejeção de parte do Ego/ Self para dentro do objeto a ser defendido. O sujeito, em um processo de expelir sua agressividade no outro, inconscientemente reedita os traços de sua personalidade que, segundo Bion (1992) e Klein (1997), projetam uma fantasia onipotente e refletem os aspectos cindidos de seu mundo interno com o desejo de eliminar o seu adversário de modo agressivo e sem certo controle egoico: um dos sintomas manifestos é a incontinência das palavras. A subjetividade do indivíduo é constituída e construída por meio do trabalho nas práticas discursivas de uma sociedade. Saber ou conhecer algo é, em termos, se apropriar dos discursos que circulam em uma sociedade e dos modos de dizê-los e de agir intrínsecos a essas práticas (BAKTHIN, 2011).

A partirdessasconsiderações, recorremos ànoção de posicionamento discursivo como o produto de uma força social identificável por meio das práticas discursivas, entendidas como maneiras em que as pessoas ativamente produzem realidades sociais e psicológicas. Dependendo das posições disponibilizadas pelas práticas discursivas, e dentro dessas práticas, atribuímos sentido a nossa própria história e a dos outros. As histórias estão localizadas dentro de um número de diferentes discursos, e por isso variam em termos da linguagem usada, dos conceitos, das questões e dos juízos morais feitos relevantes e as posições de sujeitos disponibilizados dentro deles. 


\section{Aposta analítica}

Para este ensaio, optamos por selecionar um corpus heterogêneo, mas que aportasse em uma unidade analisável. A seleção dos três vídeos deu-se por vislumbrarmos a hipótese de que havia ali indivíduos que se engajaram em um processo de identificação com uma formação discursiva, e ideológica, de poder de classes e cujas origens remetiam para um ethos ${ }^{5}$ da "aristocracia" da sociedade brasileira (DAMATTA, 1997).

A chegada do Império Português à cidade do Rio de Janeiro instaurou uma dinâmica social que cindiu a sociedade brasileira em, no mínimo, duas posições sociais: de um lado, estava a elite - quer seja econômica, cultural, quer seja da monarquia - que detinha o poder e o domínio sobre os negros e trabalhadores, escravos e ex-escravos, para os quais não era permitido ocupar as mesmas posições sociais e ou comportamentos culturais. ${ }^{6}$

Com a Proclamação da República e, mais tarde, com a conquista do Estado Democrático, os indivíduos foram alçados à categoria de cidadãos de direitos. No entanto, os discursos humanistas, que inauguraram o primado do Homem e a afirmação da igualdade entre os indivíduos, mantêm sua réplica: os discursos que filiam a um ethos da aristocracia, do poder sobre o outro e o Estado.

\subsection{Organização dos dados}

\footnotetext{
5 Ancoramos em Maingueneau $(2008 ; 2020)$ para explicar essa noção discursiva que está inserida em uma determinada situação comunicativa sóciohistórica e, por isso, ocorre em um processo de interação exercido pelo locutor em direção ao seu alocutário com a finalidade de exercer uma influência sobre este último. Trata-se de uma noção que acontece no evento discursivo de modo dinâmico e revela a amplitude da reflexividade enunciativa em uma dada cena de enunciação.

6 A complexidade das relações sociais no período colonial no Brasil e sobre como essa configuração contribuiu para a formação do povo brasileiro no século XX foi amplamente estudada por sociólogos como Gilberto Freire e Roberto DaMatta. Neste ensaio, contudo, nos interessa mobilizar tais assunções dentro da noção de formação discursiva.
}

"Sabe com quem está falando?" heterogeneidades e posicionamentos discursivos inscritos no discurso aristocrático da elite brasileira 
Para além das noções de discurso e de sujeito, já mencionadas anteriormente, tomamos como dispositivos de análise as ideias de cena enunciativa, formação discursiva e posicionamento discursivo da Análise do Discurso Francesa. De tal modo, empreendemos dois movimentos de leitura dos dados a partir da materialidade linguística: a descrição e a interpretação. Em consonância com Orlandi (2007), vislumbramos o primeiro movimento como forma de mapear a superfície material, por meio da descrição das cenas enunciativas e da análise dos elementos sintáticos dos enunciados, para entrarmos no discurso. Esse gesto de análise parte do "[...] reconhecimento de um real específico sobre o qual ela se instala: o real da língua” (PÊCHEUX, 1995, p. 50). No gesto de interpretação, visamos localizar as posições de atravessamento ideológico do discurso que apareceram nos ditos, nos modos de dizer e em seus efeitos de sentido inscritos em formações discursivas e no interdiscurso (ORLANDI, 2007).

Para descrever as cenas enunciativas dos vídeos, nós as consideraremos como CE1, CE2 e CE3. A CE1 (PM..., 2020) aconteceu em um condomínio particular, de luxo, quando a Polícia Militar, após receber uma queixa de violência doméstica, vai até o local. O vídeo foi feito por outro policial que, de dentro da viatura, filma o suspeito que grita e gesticula de modo violento com um policial militar. A CE2 (MULHER..., 2020) mostra um casal, em uma rua repleta de bares, na cidade do Rio de Janeiro que, ao serem questionados por não usarem máscaras e não respeitarem o distanciamento social preconizado pelas autoridades municipais por causa da pandemia de covid-19, desrespeitam o fiscal sanitário. A CE3 (NÃO USOU..., 2020) traz um juiz que foi multado pela Guarda Civil por andar na praia sem máscara de proteção e, nessa situação, agride os guardas civis e rasga a multa que recebeu. A composição, então, das cenas pode ser sintetizada conforme o quadro abaixo: 
Quadro 01 - Práticas/Atividades discursivas: enunciados como réplica em circulação nas Redes Sociais

\begin{tabular}{|c|c|c|c|}
\hline $\begin{array}{c}\text { Cena } \\
\text { Enunciativa } \\
(\mathrm{CE})\end{array}$ & $\begin{array}{c}\text { Situação } \\
\text { comunicativa }\end{array}$ & Formação discursiva & $\begin{array}{c}\text { Posicionamento } \\
\text { discursivo }\end{array}$ \\
\hline $\begin{array}{l}\text { CE1. Morador de } \\
\text { condomínio de } \\
\text { luxo de SP: “aqui é o } \\
\text { Alphaville” }\end{array}$ & $\begin{array}{l}\text { Casal com filho } \\
\text { (mulher segura } \\
\text { criança no colo) na } \\
\text { porta de casa, e o } \\
\text { homem agride um } \\
\text { policial no lugar } \\
\text { da Autoridade do } \\
\text { Estado Brasileiro - } \\
\text { Instituição }\end{array}$ & $\begin{array}{c}\text { Discurso "aristocrático" } \\
\text { colonial brasileiro } \\
\text { hierarquizado/elitizado }\end{array}$ & $\begin{array}{l}\text { "Você sabe } \\
\text { com quem está } \\
\text { falando?" }\end{array}$ \\
\hline $\begin{array}{l}\text { CE2. Mulher que } \\
\text { discutiu com } \\
\text { fiscal no Leblon: } \\
\text { "cidadão, não } \\
\text { engenheiro civil". }\end{array}$ & $\begin{array}{c}\text { Casal na rua } \\
\text { agride um fiscal } \\
\text { da vigilância } \\
\text { sanitária no lugar } \\
\text { da Autoridade do } \\
\text { Estado Brasileiro - } \\
\text { Instituição }\end{array}$ & $\begin{array}{c}\text { Discurso "aristocrático" } \\
\text { colonial brasileiro } \\
\text { hierarquizado/elitizado }\end{array}$ & $\begin{array}{l}\text { "Você sabe } \\
\text { com quem está } \\
\text { falando?" }\end{array}$ \\
\hline $\begin{array}{c}\text { CE3. } \\
\text { Desembargador } \\
\text { é multado e } \\
\text { agride Guarda } \\
\text { Civil Municipal: } \\
\text { "Analfabeto e } \\
\text { otário." }\end{array}$ & $\begin{array}{c}\text { Desembargador } \\
\text { caminhando na praia } \\
\text { sem máscara agride } \\
\text { um guarda civil } \\
\text { municipal no lugar } \\
\text { da Autoridade do } \\
\text { Estado Brasileiro - } \\
\text { Instituição }\end{array}$ & $\begin{array}{l}\text { Discurso “aristocrático" } \\
\text { colonial brasileiro } \\
\text { hierarquizado/elitizado }\end{array}$ & $\begin{array}{l}\text { "Você sabe } \\
\text { com quem está } \\
\text { falando?" }\end{array}$ \\
\hline
\end{tabular}

Fonte: elaborado pelos autores

Em todas as cenas enunciativas, os sujeitos são solicitados por agentes do Estado a obedecer a uma ordem e se recusam a fazê-lo, mas, para legitimar esse ato, precisam batalhar discursivamente para ocupar um lugar de poder acima de quem os interpela. Essa negociação instaura, então, um movimento de réplica no qual o sujeito assume um posicionamento de identificação com formação discursiva do "sabe com quem está falando?", na qual há o poder (quase) irrestrito e há a permissão de desobediência ao Estado. Os enunciados da ordem "sabe com quem está falando?” produzem 
o efeito de sentido de hierarquia porque projetam um enunciador que tem mais poder sobre o seu interlocutor. É, portanto, um projeto discursivo que se assenta em uma posição-sujeito que tem a vontade de marcar o seu poder sobre um outro.

No Quadro 01, podemos entender que o conceito de cena enunciativa, sob a perspectiva de Maingueneau (2008), está posto de modo a indicar o espaço constitutivo de materialização do discurso. A situação comunicativa se apresenta em um diálogo de enunciadores e coenunciadores e nestes coloca em cena, em determinado lugar e num momento de enunciação, um modo de dizer constitutivo. $\mathrm{O}$ interdiscurso organiza os elementos de união e dispersão de uma rede de textos/discursos que possibilitarão a emergência e a circulação de enunciados que, necessariamente, supõem conflito permanente com diversos posicionamentos.

Já os enunciados, sob o prisma de Volóchinov (2017), estão cheios de vozes oriundas do ambiente que os constituem, isto é, do heterodiscurso dialogizado que se estabelece em uma cadeia de responsividade em que se encontra o sujeito do discurso. Este, por sua vez, vai responder às palavras alheias por meio de diversas produções verbais: réplicas, adesões, ironias, críticas, dissonâncias, que estão ativamente relacionadas com o auditório social que o rodeia.

Retomando a noção de posicionamento estabelecida em nossos estudos (BRITO, 2019), as histórias estão localizadas dentro de um número de diferentes discursos, motivo pelo qual variam em termos da linguagem usada, dos conceitos, das questões e dos juízos morais relevantes, assim como as posições de sujeitos disponibilizadas dentro deles. Ampliamos a noção de posicionamento nesta análise como uma possibilidade de engajamento e identificação, via interdiscurso, aos modos de dizer e aos efeitos de sentido com outros discursos.

Os modos de dizer podem indicar, segundo Maingeneau (2008), as características dos grupos que os produzem e os fazem circular, nutrindoos de valores dentro de determinadas comunidades discursivas que acabam partilhando ritos, normas e padrões em que emergem dizeres em discursos constituintes ("sabe com quem está falando?"). Esses discursos não acionam somente autores, mas uma plêiade de posições e papéis sociodiscursivos. Nossas análises nos levam a considerar que os posicionamentos postos em jogo nas cenas enunciativas dos vídeos analisados se filiam a um mesmo 
espaço do discurso de poder, e revelam o interdiscurso (MAINGUENEAU, 1997).

Os posicionamentos discursivos que se estabelecem ao longo dos ditos analisados assentam em: 1) desqualificar o seu oponente; 2) convocar vozes aliadas que significam uma autoridade hierarquicamente superior à do interlocutor; 3) mobilizar um ethos que projeta um poder maior do que o de seu adversário. Assim, ancorados nos elementos referidos por DaMatta (1997) a respeito dos pilares sobre os quais se funda o discurso de poder do "sabe com quem está falando?", analisamos os índices e marcas linguísticodiscursivas que indicam a adesão às noções de pessoalidade (eu sei, eu sou, eu tenho, eu conheço), à filiação a uma rede de influências e à eliminação ou anulação do outro.

O movimento de desqualificar o outro é realizado por meio do uso de enunciados como apresentado no Quadro 2.

\section{Quadro 2- Anular o interlocutor}

\begin{tabular}{c|l}
\hline CE1 & $\begin{array}{l}\text { Você é um bosta... É um merda de um PM que ganha mil reais por mês, eu } \\
\text { ganho } 300 \text { mil reais por mês. Quero que você se foda, seu lixo do caralho. }\end{array}$ \\
\hline CE2 & $\begin{array}{l}\text { Como você mediu [o distanciamento social]? Cadê sua trena? Cidadão, não. } \\
\text { Engenheiro civil, formado. Melhor do que você. }\end{array}$ \\
\hline CE3 & $\begin{array}{l}\text { Estou aqui com um analfabeto, eu expliquei, e eles não conseguem entender. } \\
\text { O Sr. sabe ler? [ao mostrar a carteira de identidade para o guarda municipal]. }\end{array}$ \\
\hline
\end{tabular}

Fonte: elaborado pelos autores.

Tomando uma posição analítica, flagramos na CE1 que o sujeito enunciador se põe em posição de réplica, de modo agressivo, para anular o outro que o interpela. $\mathrm{O}$ outro é qualificado como um objeto que deve ser destruído - visto que não tem valor - acionando o mecanismo inconsciente de identificação projetiva: o policial é um lixo; aquilo que poderia ser jogado fora. É também um merda ou um bosta, não serve, não tem efeito.

$\mathrm{Na}$ CE2, um casal que está em uma rua do Leblon, na cidade do Rio de Janeiro, e sai em direção ao fiscal da vigilância sanitária (superintendente de Educação e de Projetos), que recebe a seguinte provocação: "[eu] posso falar com o seu chefe, não?!" e [eu] quero saber como você mediu as pessoas". E depois : "cidadão não, engenheiro civil formado, melhor do que você!" 
Os ditos, que visam a anular o interlocutor, demonstram que a identificação com a formação discursiva do "sabe com quem está falando?" tem um propósito bélico, atravessado pelo desejo de ser alguém que está acima da lei. Assim, é preciso desmoralizar o interlocutor, anular a sua existência, para que ele recue de sua ordem. Nesse processo, os sujeitos falantes lançam mão de artifícios discursivos, gestos não verbais e aderem a uma série de símbolos que os filiam em lugares historicamente marcados como de poder social ou financeiro: "Aqui é o Alphaville", "Cidadão, não. engenheiro civil, formado", "Estou aqui com um analfabeto" "O Sr. sabe ler?" [ao mostrar a carteira de identidade - de desembargador - para o guarda municipal]. Os gestos não verbais, realizados pelos locutores, são expressos de modo agressivo e manifestados em "um partir para cima" dos representantes da autoridade estatal tal qual aparecem nas cenas enunciativas 1, 2, e 3: movimento de braço, dedo em riste e o ato de rasgar o papel que continha a multa.

$\mathrm{Na}$ CE2, o modo de dizer enunciado pelo casal, primeiro pelo homem e depois pela mulher, revela um elemento essencial de uma marca linguístico-dicursiva que é vestígio da negociação do sujeito com a hetereogenidade constitutiva da língua(gem), pois desvela o dizer atrelado à ilusão de que o sujeito é fonte de sentido e, por esse motivo, se põe em cena como aquele que tem uma força, não só da palavra, mas do agir, e está abalizado a partir para cima do outro-semelhante que não é considerado, não é visto, ou melhor, nem tratado como igual: [posso falar como seu chefe] e [cidadão não, engenheiro civil formado, melhor do que você!]

Esse gesto simbólico de dizer do sujeito (casal que ocupa esse lugar de dizer) que entra em dialógo com o fiscal pode mostrar-nos a voz social do: "você sabe com quem está falando?" que está atrelada à formação discursiva do autoritarismo representada e que emana o discurso aristocrático colonial brasileiro hierarquizado/elitizado.

O segundo posicionamento discursivo aparece como intenção de demonstrar a filiação do enunciador a uma rede de amizades e de influências. Assim, os ditos sinalizam para as adesões que o sujeito faz em um campo discursivo em relação aos sistemas de valores que aí circulam, não de forma absoluta ou estanque, mas em função dos discursos que ele mesmo produz tal qual se apresenta no quadro a seguir: 


\section{Quadro 3 - Marcar a filiação a uma rede de amizades e de influências}

\begin{tabular}{l|l}
\hline CE1 & $\begin{array}{l}\text { Você é secretário, vem para cá e me ajuda. } \\
\text { Marinho vem pra cá agora, traz o secretário de segurança, traz o secretário que } \\
\text { tiver que trazer. }\end{array}$ \\
\hline CE2 & Não vai chamar seu chefe? \\
\hline CE3 & $\begin{array}{l}\text { Eu vou ligar para o Del Bel. } \\
\text { Del Bel, eu estou aqui com um analfabeto e eu disse a ele que não é ele quem } \\
\text { fala comigo. Sou eu quem falo com o Del Bel. }\end{array}$ \\
\hline
\end{tabular}

Fonte: elaborado pelos autores.

Em uma situação comunicativa entre interlocutores, os posicionamentos discursivos de um sujeito falante, em seu modo de dizer, revelam o seu trabalho com a língua(gem) nos modos de dizer e nos ditos que deixam entrever atravessamentos e interpelações do sujeito do discurso. Ao marcar que conhece uma instância de poder - localizada na figura de indivíduos -, que ocupa cargos superiores àquele que o interpela, o sujeito volta-se a uma dinâmica do embate para a qual há a necessidade de aliados: [Marinho, vem pra cá agora, traz o secretário de segurança, Não vai chamar seu chefe, eu vou ligar para o Del Bel]. O modo de negociar um suposto poder inclui clamar por um outro com o qual se mantém uma rede de amizade, de troca, de intimidade e que irá permitir-lhe descumprir a ordem que lhe é imposta na situação.

Os indivíduos ameaçam seus interlocutores com a possibilidade da intervenção de outrem, e isso sinaliza a não uniformidade do campo discursivo do poder, visto que há diferentes níveis e lugares de autoridade. Se é pressuposto que o Estado deve vigiar e fiscalizar os cidadãos de modo igualitário, a formação discursiva do "sabe com quem está falando?" legitima a possibilidade de individualizar esse poder por meio do jeitinho brasileiro. Em intrínseca relação com esse posicionamento, há o terceiro posicionamento discursivo por meio do qual o dito marca sua construção de autoridade em relação ao interlocutor como se desenha no quadro em seguida: 


\section{Quadro 4 - Legitimar a pessoalidade do poder econômico e/ou intelectual na pauta do eu sou - eu sei - eu tenho}

\begin{tabular}{l|l}
\hline CE1 & $\begin{array}{l}\text { Você não me conhece; } \\
\text { Você pode ser macho na periferia, mas aqui você é um bosta; } \\
\text { Aqui é Alphaville, mano. } \\
\text { eu ganho } 300 \text { mil reais por mês. }\end{array}$ \\
\hline CE2 & $\begin{array}{l}\text { A gente paga você, filho. } \\
\text { O seu salário sai do meu bolso } \\
\text { Cidadão, não. Engenheiro civil formado, melhor do que você }\end{array}$ \\
\hline CE3 & $\begin{array}{l}\text { O Sr. sabe ler? Então leia esse documento aqui [a carteira mostrava que era um } \\
\text { desembargador]. } \\
\text { Você sabe o que é essa carteira? }\end{array}$ \\
\hline
\end{tabular}

Fonte: elaborado pelos autores.

Tomando a CE1 para análise, temos o dito "Aqui é o Alphaville" que instaura dois espaços: o aqui [Alphaville] e o aí [periferia]. O dêitico aqui marca a divisão entre o eu e tu e sinaliza, para o interlocutor, acerca do "sabe com quem está falando?" porque o aqui é o meu território, eu ocupo e circulo em um espaço diferente do $t u$. O uso do substantivo Alphaville recupera, por meio da memória discursiva, sentidos em torno de riqueza e de poder. Em seguida, o sujeito diz: ["você é um bosta, você é um merda de um PM que ganha tezentos reais por mês, eu ganho trezentos mil por mês, eu quero que você se foda... você pode ser um macho na periferia, mas aqui você é um bosta"] e repete "[Aqui é o Alphaville, mano.]" O fragmento [você pode ser macho na periferia, mas aqui você é um bosta] também indicia para a instabilidade inerente ao exercício de poder. O policial ocupa um lugar de poder e seu interlocutor reconhece isso ao dizer que [pode ser macho na periferia], contudo esse poder é limitado em territórios frequentados pela elite econômica. Os moradores do Alphaville seriam supostamente diferentes dos moradores da periferia, pois o poder econômico, para os sentidos negociados nesta formação discursiva, se sobrepõe ao poder institucional.

Cabe destacarmos o efeito simbólico do verbo ganhar: primeiro empregado no modo do presente do indicativo antecedido do pronome pessoal: "eu ganho..." que, na perspectiva enunciativa de Benveniste (1989), é como o eu locutor - categoria de pessoa - se coloca no discurso 
dirigindo-se para, nesse caso, o PM (outra pessoa). Nesse modo de dizer flagramos, com o uso do mesmo verbo na terceria pessoa do singular do modo do presente do indicativo: "você ganha...", que o PM não é tratado/ considerado, no discurso, pois o você recebe o estatuto de (não-dito) ele categoria de não pessoa - como um objeto e ou referente. A conjugação verbal a qual o seu locutor se reporta e pronuncia confirmando assim sua provável identificação com o atravessamento do discurso "aristocrático" da não igualdade que circula com força e carga expressiva no nosso País, especialmente nas camadas ricas da população que, ao que parece, se consideram, pelos menos no modo de dizer, herdeiros de "suposta" elite brasleira.

Nas CE2 e CE3, os ditos também se inscrevem na legitimação da pessoalidade, do eu sou e eu sei, ali convocados por meio dos símbolos de poder intelectual. Temos o dizer de sujeitos que têm a ilusão de ser a fonte do sentido do seu dito e, por isso, enunciam eu sei o que eu digo e sei quem sou:[a gente paga você, filho, o seu salário sai do meu bolso] [você sabe ler? Então leia aqui], eu sou aquele que pode falar: [cidadão, não, engenheiro civil, formado, melhor do que você], [você sabe o que é essa carteira?]. O processo de se contraidentificar com os sentidos do ser cidadão e de se projetar como bacharel em engenharia civil ou como desembargador indiciam os significados que a formação acadêmica e a posição profissional tem na sociedade brasileira. $\mathrm{O}$ cidadão seria qualquer um e, por consequência, é alguém destituído de poder. Dizer que é melhor do que um agente do Estado, quer seja porque é engenheiro civil formado ou por ser desembargador, visa marcar o pertecimento a elite intelectual, acionando, via interdiscurso e da memória histórica, os sentidos em torno do que é pertencer a essa casta, principalmente em profissões historicamente da aristocracia como a Engenharia Civil, Medicina ou Direito. Tradicionalmente, ainda há a percepção do título acadêmico como um símbolo que diferencia o cidadão comum do 'doutor'.

Todos os trechos analisados demonstram que uma das vidas pelas quais o sujeito discursiviza a sua identificação com os ditos da pauta do "sabe com quem está falando?" de uma formação discursiva da aristocracia brasileira é o processo de materializar o seu pertencimento a uma elite econômica e cultural. 


\section{Considerações finais}

Neste ensaio, intentamos descrever os processos discursivos dos quais os sujeitos lançaram mão para indiciar a sua identificação com uma formação discursiva de poder da aristocracia brasileira. Pêcheux (1995, p. 172) tratou a formação discursiva “(...) como espaço de reformulaçãoparáfrase onde se constitui a ilusão necessária de uma 'intersubjetividade falante' pela qual cada um sabe de antemão o que o 'outro' vai pensar..., e com razão, já que o discurso de cada um reproduz o discurso do outro."

Apoiados nessas considerações, nossa análise descreveu de quais modos o sujeito reformulou os sentidos inscritos no campo discursivo da elite brasileira com um propósito bélico para destruir o seu interlocutor. Alicerçamo-nos nas considerações de DaMatta (1997, p. 275) que tratou a sociedade brasileira como “(...) hierárquica, familista, patrimonialista e que aprova tanto o 'jeitinho', quanto um amplo leque de comportamentos similares" e que, nessa dinâmica, opera com duas posições sociais complementares: a do indivíduo e da pessoa. $\mathrm{O}$ indivíduo seria o cidadão comum que deve e precisa pautar-se pelo regime das leis universais e institucionais. Já a noção de pessoa alude ao sujeito do poder econômico e/ou intelectual fundado na individualização e na pessoalidade e para o qual há legitimado os privilégios de poder dizer, poder mandar, poder desobedecer.

Tais posições sociais, contudo, não são intrínsecas ao indivíduo e são desestabilizadas em determinadas situações. Quando isso ocorre, o sujeito do discurso aristocrático precisa legitimar o seu poder financeiro, intelectual e sua rede de influências. A batalha ideológica e discursiva pela manutenção dessa hierarquia materializa-se em ditos, conforme exemplificados neste ensaio, que projetam o "sabe com quem está falando?" e "quem é você para falar assim comigo, que sou hierarquicamente superior a você?".

A formação discursiva da disputa de classes tem tomado atualmente contornos mais autoritários e beligerantes, e para os quais o igualitarismo deve ser combatido em sua raiz. No contexto brasileiro, o indivíduo quando diz "sabe com quem está falando?" está envolvido em uma situação na qual sente a sua autoridade diminuída e/ou ameaçada e, como consequência, tem o desejo de fazer parecer, de forma cabal e definitiva, o seu suposto 
poder para anular o outro (DAMATTA, 1997). Na perspectiva linguísticodiscursiva da qual partimos, o processo de identificação com os efeitos de sentido da ordem do "sabe com quem está falando?" emerge a partir da desestabilização de lugares de poder. Consequentemente, o sujeito se engaja em um projeto discursivo que, inconsciente ou conscientemente, precisa marcar o seu interlocutor a um lugar menor e de objeto a ser destruído.

\section{Referências}

AUTHIER-REVUZ, J. Heterogeneidade mostrada e heterogeneidade constitutiva: elementos para uma abordagem do outro no discurso. In: AUTHIER-REVUZ, J. Entre a transparência e a opacidade: um estudo enunciativo do sentido. Porto Alegre: EDIPUCRS, 2004. p. 11-80.

BAKHTIN, M. Estética da criação verbal. Tradução de Paulo Bezerra. 6. ed. São Paulo: Martins Fontes, 2011.

BENVENISTE, Émile. O aparelho formal da enunciação. In: BENVENISTE, E. Problemas de linguística geral II. São Paulo: Pontes, 1989. p. 81-90

BION, R. Wilfred. Conversando com Bion: quatro discussões com W. R. Bion. Tradução Paulo César Sandler. Rio de Janeiro: Imago, 1992.

BRITO, Robson Figueiredo. Posicionamentos discursivos e identitários de sujeitos universitários em experiência de letramento acadêmico em um curso de Direito. 2019. Tese (Doutorado em Letras) - Programa de Pós-graduação em Letras, PUC Minas, Belo Horizonte, 2019.

DAMATTA, Roberto. Sabe com quem está falando? Um ensaio sobre a distinção entre indivíduo e pessoa no Brasil. In: DAMATTA, Roberto. Carnavais, malandros e heróis: para uma sociologia do dilema brasileiro. Rio de Janeiro: Rocco, 1997. p. 179-248.

GINZBURG, C. Sinais: raízes de um paradigma indiciário. In GINZBURG, C. Mitos, emblemas e sinais. São Paulo: Companhia das Letras, 1986. p. 143-179. 
KLEIN, Melanie. Sobre a identificação. In: KLEIN, Melanie. Inveja e gratidão e outros trabalhos. Tradução A. Cardoso. Rio de Janeiro: Imago, 1997. p. 169-204.

MAINGUENEAU, Dominique. Cenas da enunciação. Organizado por Sírio Possenti e Maria Cecília Pérez de Souza-e-Silva. Curitiba: Criar Edições. 2008. 183 p.

MAINGUENEAU, Dominique. Novas tendências em Análise do Discurso. Tradução Freda Indursky. 2. ed. Campinas: Pontes, 1997.

MAINGUENEAU, Dominique. Variações sobre o ethos. Tradução de Marcos Marcionilo. São Paulo: Parábola, 2020.

MULHER que aparece em vídeo agredindo verbalmente fiscal da vigilância no Rio é demitida. 7 jul. 2020. São Paulo. 1 vídeo (2 min). Disponível em: $<$ https://globoplay.globo.com/v/8679253/>. Acesso em: 20 set. 2020.

NÃO USOU máscara: desembargador humilha guardas após ser multado. 20 jul. 2020. São Paulo. 1 vídeo (2.45 min). Band Jornalismo. Disponível em: <https://www.youtube.com/watch? v=Emth4dhD 7g\&feature=youtu. be>. Acesso em: 20 set. 2020.

ORLANDI, Eni P. Análise de Discurso: princípios e procedimentos. 3. ed. Campinas: Pontes, 1999.

ORLANDI, Eni P. Interpretação: autoria, leitura e efeitos do trabalho simbólico. 5. ed. Campinas: Pontes, 2007.

PÊCHEUX, Michel. Semântica e discurso: uma crítica à afirmação do óbvio. 2. ed. Tradução de Eni P. Orlandi et al. Campinas: Editora da UNICAMP, 1995.

PM xingado por empresário em Alphaville processará agressor por danos morais. 01 jun. 2020. 1 vídeo (2 min). São Paulo. Band Jornalismo. Disponível em: <https://www.youtube.com/watch? $\mathrm{v}=\mathrm{NeNstxxYQfI}>$. Acesso em: 20 set. 2020.

TIFOUNI, Leda Verdiani, PEREIRA, Anderson de Carvalho. Análise Indiciária: uma topologia das singularidades. TIFOUNI, Leda Verdiani, 
PEREIRA, Anderson de Carvalho, MILANEZ, Nilton (org.) O paradigma indiciário e as modalidades de decifração nas Ciências Sociais, São Paulo, EdUFSCar. 2018, p. 121-148.

VOLÓCHINOV, Valentin (Círculo de Bakhtin). Marxismo e filosofia da linguagem. Problemas fundamentais do método sociológico na ciência da linguagem. São Paulo: Editora 34, 2017. 